\title{
La potestad normativa de la Agencia Nacional de Contratación Pública - Colombia Compra Eficiente en el sistema de fuentes de derecho en la contratación estatal
}

The regulatory power of the Agencia Nacional de Contratación Pública - Colombia Compra Eficiente (National Public Procurement Agency - Colombia Efficient Purchase) within the legal source system of state procurement

\section{Luz Astrid Álvarez Patiño}

Magíster en Derecho

Universidad de Antioquia, Medellín - Colombia.

Correo: luzastrid15@yahoo.com

\section{Resumen}

Entre la fuerte reserva legal, un estatuto de principios y la autonomía administrativa, se creó Colombia Compra Eficiente como ente rector en la contratación estatal y sus instrumentos producen ciertas alteraciones en la dinámica contractual. Por ello, a partir de una investigación dogmática iuspositivista y enfoque cualitativo, se estudia las posibles competencias normativas de esta entidad, distinguiendo su naturaleza, alcance, efectos e impacto en el sistema de fuentes. Se advierte como principal conclusión que, por razones materiales, los instrumentos normativos tienen la vocación de auténticas normas dentro del sistema de fuentes de derecho que restringen 
la autonomía y discrecionalidad de las entidades públicas e imponen fuertes retos sobre su alcance, control y legalidad.

\section{Palabras Clave:}

Colombia Compra Eficiente - Fuentes de derecho administrativo - Potestad normativa - Reserva legal - autonomía administrativa - derecho blando.

\section{Abstract}

Between the strong law-only regulation, a statute of principles, and the administrative autonomy; Colombia Compra Eficiente was created as the governing body for state procurement and its instruments produce certain alterations in contractual dynamics. Hence, based on a dogmatic legal positivist investigation and qualitative approach, in which documentary techniques prevail, the public entities' inquiries and interviews, the possible normative competencies of this entity are studied, discerning their nature, reach, effects and impact within the source system. It is noted as the main conclusion based on the stand assumed by Colombia Compra Eficiente, supervisory agencies and experts in the subject that, due to material reasons, the legal instruments have the quality of authentic laws within the legal source system which restrict the autonomy and discretionarily of public entities and impose strong challenges regarding their scope, control and legality.

\section{Key Words:}

Colombia Compra Eficiente; sources of administrative law; regulatory power; law-only regulation; administrative autonomy; soft law.

\section{Introducción}

Con la expedición del Estatuto General de Contratación de la Administración Pública (EGCAP) -Ley 80 de 1993-, el desarrollo normativo de la contratación ha estado entre la reserva legal y la autonomía contractual de los entes públicos, al pretender corregir el carácter excesivamente reglamentario de los

\section{Cómo citar este artículo:}

Álvarez Patiño, L. A. (2020). La potestad normativa de la Agencia Nacional de Contratación Pública - Colombia Compra Eficiente en el sistema de fuentes de derecho en la contratación estatal. Revista de la Facultad de Derecho y Ciencias Políticas, 50 (132), pp. 50-79. doi: http://dx.doi.org/10.18566/ rfdcp.v50n132.a03

Recibido: 28 de abril de 2019.

Aprobado: 01 de agosto de 2019. 
anteriores estatutos para erigirse como un estatuto general y de principios. Sin embargo, la corrupción, la descoordinación de las entidades públicas y el descontrol de la producción normativa impulsaron en el 2011 la creación de la Agencia Nacional de Contratación Pública -Colombia Compra Eficiente-, como ente rector y organismo técnico especializado de la contratación estatal.

Las funciones y actuaciones de CCE generan una fuerte intervención en la gestión contractual -no prevista inicialmente en el EGCAP- a partir de la expedición de circulares, manuales, guías, estándares, lineamientos, entre otros instrumentos que revisten un carácter novedoso, desconocido y exótico en el sistema de fuentes de derecho en materia contractual, donde ha prevalecido una fuerte reserva legal y un reducido margen de acción a la potestad reglamentaria. Por tanto, la pregunta de este trabajo es: ¿Cuál es el alcance normativo de los instrumentos expedidos por la Agencia Nacional de Contratación Pública -Colombia Compra Eficiente (en adelante CCE)- como órgano rector de la contratación estatal dentro del sistema de fuentes de derecho en la contratación estatal?

En efecto, ante el silencio del legislador frente al rol normativo de CCE, el alcance de sus competencias frente a la autonomía administrativa de las entidades públicas -especialmente territoriales y exceptuadas de la Ley 80 de 1993 (Ley 80, 1993)-, la naturaleza, efectos y consecuencias de sus instrumentos, se determinará el carácter vinculante de los mismos, a partir de un análisis dogmático donde se evidenciará que las herramientas de CCE son auténticas normas con efectos vinculantes graduales. Con ellas se insertan prácticas contractuales internacionales influenciadas por la globalización y flexibilización de instrumentos para lograr de manera eficiente los cometidos estatales.

Este trabajo es dogmático, se desarrolla bajo el paradigma del positivismo jurídico, prevalece el enfoque cualitativo y la técnica documental, porque se parte del estudio las posibles competencias normativas de CCE, se distingue su alcance y funciones, de acuerdo con las disposiciones jurídicas, interpretaciones y dogmas del derecho vigente. Además, se analizan los instrumentos expedidos por CCE, la posición de CCE, los órganos de control y maestros como Fabián Marín, José Luis Benavides, Juan David Osorio, David Suárez, Jorge Iván Duque y Willington Gil y se estudia la jurisprudencia del Consejo de Estado. 
En estos términos se aborda: 1. El sistema de fuentes de derecho en la contratación estatal. 2. La Agencia Nacional de Contratación Pública - CCE como ente rector, su naturaleza, funciones y roles en el marco de la contratación estatal. 3. La naturaleza y fuerza vinculante de los instrumentos expedidos por CCE dentro del sistema de fuentes de derecho.

\section{El sistema constitucional de fuentes de derecho en la contratación estatal: entre la reserva legal y la libertad contractual}

El diseño constitucional de las fuentes de derecho en la contratación estatal se define desde la Constitución Política en los artículos 4, 6, 121 y 150 inciso final, donde se consagra la prevalencia de las normas constitucionales, el principio de legalidad y la competencia del Congreso de la República para "expedir el estatuto general de contratación de la administración pública y en especial de la administración nacional” (Constitución Política, 1991, art. 150).

En consecuencia, prevalece la reserva legal y la libertad de configuración legislativa. En efecto, el constituyente y el legislador definen el sistema de fuentes en la contratación estatal, el cual se caracteriza por: i) la ley como fuente privilegiada en atención a la reserva legal y el principio de libre configuración legislativa; ii) la ley impulsa a las otras fuentes del derecho como restricciones de la autonomía administrativa de las entidades públicas; iii) los reglamentos surgen como manifestaciones de la necesidad de la potestad reglamentaria del Presidente de la República y la autonomía administrativa y/o territorial de las entidades públicas; y iv) la vanguardia de nuevas restricciones a la autonomía administrativa.

Bajo la primera característica, los únicos límites constitucionales del legislador son la autonomía de los entes territoriales -Constitución Política, 1991, art. 287- y la potestad reglamentaria praeter legem para la contratación con entidades privadas sin ánimo de lucro y de reconocida idoneidad Constitución Política, 1991, art. 355-. Fuera de estos se impone la fuerza de ley como suprema manifestación de voluntad del Estado, con la más elevada posición desde el punto de vista jerárquico (con salvedad de la Constitución) y una ilimitada fuerza expansiva que le permite imponerse en todos los ámbitos (De Otto, 2001), que ostenta una fuerte legitimidad por ser manifestación del principio democrático. 
La Corte Constitucional reconoce el alcance absoluto de la reserva legal con fundamento en el artículo 150 constitucional. Así: "las normas sobre contratación administrativa, generales o especiales, tienen reserva de ley. En otras palabras, las mismas no pueden ser expedidas por el gobierno en ejercicio de facultades reglamentarias”. (Corte Constitucional, Sentencia C-491, 2007). Este imperativo implica que el legislador ha de establecer por sí mismo la regulación y no puede remitirla a normas distintas -tiene prohibida la deslegalización- (De Otto, 2001).

La reserva legal se ha delimitado jurisprudencialmente en materias como los procedimientos de selección (Corte Constitucional, Sentencias C-491/97 y C-508/02 y Consejo de Estado, Exp. 37.785, 36054 y 39093), la tipificación de los negocios jurídicos, la atribución de costos del proceso de selección, la subsanación de los requisitos habilitantes, el establecimiento de formas diferentes de remuneración en la concesión y la introducción de cláusulas limitativas en la contratación.

En segundo lugar, conforme al principio de libre configuración legislativa, el EGCAP como ley ordinaria definió el sistema de fuentes normativas y pretendió corregir la multiplicidad y dispersión normativa, el carácter reglamentario y casuístico de los anteriores estatutos y, por esto, se erigió como una ley de principios. En la doctrina se califica como un estatuto único y un estatuto de principios (Dávila Vinueza, 2001, p. 10) y en la jurisprudencia como un estatuto general y principialistico (Corte Constitucional, Sentencia C-949/01 y C-126/16)

El legislador privilegió la ley, de derecho público o privado (Ley 80, 1993, arts. 13, 32, 40 y 77) y la autonomía de la voluntad, que conforme a los principios del EGCAP y, consensuada, también será ley para las partes. Esta autonomía se privilegia al erigirse la Ley 80 como un estatuto de principios, entendidos como mandatos de optimización realizables por sus destinatarios las entidades públicas- en la mayor medida dentro de las posibilidades fácticas y jurídicas (Alexy, 1993). En estos términos, se da un papel protagónico a la autonomía de la voluntad y un reducido ámbito de acción a las otras fuentes del derecho.

La autonomía de la voluntad implica que "la voluntad del hombre -de las entidades públicas- (frente a la del legislador) tiene la aptitud de darse su propia ley" (Benavides, 2008, p. 96), es una "independencia constituida por el Derecho” (Schimdt-Assmann, 2003, p. 212) que se manifiesta en las 
entidades públicas como libertad contractual (Benavides, 2008), autonomía administrativa como atributo de las personas jurídicas públicas (Ley 489 de 1998), autonomía territorial como principio constitucional (Constitución Política, 1991, art. 287) y discrecionalidad administrativa como noción de la teoría del derecho administrativo (Díaz, 2013; Schimdt-Assmann, 2003).

Ahora bien, la reserva legal impone mínimamente la expedición del EGCAP y al expedirse como un estatuto de principios se adoptó la técnica de los principios que no requieren un desarrollo posterior o intermediación a través del reglamento; sino unas bases para la actuación inmediata (Benavides, 2014; Santaella, 2017). En consecuencia, se restringe el poder reglamentario: por un lado, no son necesarias más fuentes normativas porque se tienen los principios necesarios para su aplicación y, por otro lado, la realización de los principios está a cargo de los destinatarios.

En este sentido, Benavides señala que las omisiones del legislador no son tales; sino auténticos ámbitos de libertad para el ejercicio de la autonomía de la voluntad administrativa (2014). Por lo tanto, las demás fuentes del derecho son restricciones a la autonomía administrativa, que limitan sus contornos y margen de acción.

En tercer lugar, se expiden los reglamentos como manifestaciones de la necesidad de la potestad reglamentaria del Presidente de la República y la autonomía administrativa y/o territorial de las entidades públicas. Por reglamento se entiende el "acto administrativo, de carácter general, que tiene vocación de permanencia en el tiempo y que se expide en ejercicio de la función administrativa” (Marín, 2015, p. 9).Su expedición se justifica por la imposibilidad de que el poder legislativo pueda prever todas las contingencias de la ejecución de las leyes y por la atribución dentro del ordenamiento jurídico de esta potestad a la Administración (Entrena Cuesta, 1965; De Otto, 2001).

Con el EGCAP se presentan múltiples discusiones sobre la potestad reglamentaria, su alcance y titulares. Existe consenso en que el Presidente de la República tiene competencia reglamentaria a nivel general, siempre y cuando sea necesaria para la cumplida ejecución de las leyes (Constitución Política, 1991, artículo 189 numeral 11) y, de manera tenue, se reconoce la competencia de las entidades para reglamentar los asuntos a su cargo (Consejo de Estado, Sentencia del 19 de agosto de 2004, exp. 2473-01; Sentencia del 11 de abril de 2019, exp. 52.055), a través de los Manuales de Contratación y de los Pliegos de condiciones de los procesos contractuales. 
La potestad reglamentaria se encuentra limitada por el principio de reserva legal y tiene como límites generales la necesidad y un contenido legal mínimo -objeto y finalidad de la potestad- (Corte Constitucional, Sentencias C-219/17 y C-644/16; Benavides, 2014). A pesar de la reserva legal, la presencia de la función legislativa se ha visto opacada ante la potestad reglamentaria que ha tomado un papel protagónico (Safar, 2017). Se ha producido una hiperinflación reglamentaria ante la necesidad de instrumentos temporales, ágiles y adaptables a las circunstancias del mercado económico, que imponen nuevos retos en el sistema de fuentes.

En cuarto lugar, surgen nuevas restricciones a la autonomía administrativa debido a las nuevas tendencias del derecho administrativo, que revalúan la potestad reglamentaria para introducir nuevos instrumentos, más ágiles, que garanticen más gobernanza, mejores prácticas y contrarresten la corrupción.

Así, a nivel nacional se cuestiona si esta potestad está concentrada en el Presidente de la República o se puede dispersar en otras autoridades entidades destinatarias, ministerios, departamentos administrativos-. A nivel internacional se revalúa esta potestad normativa ante la existencia de sistemas de contratación pública jerarquizados con entidades tutoras, de planeación o rectoras en la materia, que expiden normas generales (Nicaragua), impulsan la máxima competencia económica (Chile), proponen, impulsan y siguen políticas públicas (Argentina y Uruguay) y dictan actos administrativos que dan cumplimiento a la ley y el reglamento (Panamá) (Benavides, 2016; Morón, 2018).

El Estado-nación se ha atomizado y fragmentado en varias direcciones (Sarmiento, 2011, Mir Puigpelat, 2004), la presencia de la función legislativa se ha visto opacada y la potestad reglamentaria ha tomado un papel protagónico. El legislador motorizado se ve desplazado por la administración motorizada con una producción reglamentaria creciente y expansiva. Estamos ante una "realidad jurídica rampante”, una "administración publica posmoderna” o “administración corporativa” (Martínez, 2018, p. 291), donde la potestad normativa se difumina en las autoridades y surgen fuentes del derecho más dúctiles para la gestión pública.

Surge la regulación y se incorporan instrumentos flexibles como una tendencia y transformación del derecho administrativo (Suárez, 2010 y 2013; Ariño, 2003). Incluso, se afirma que surge "una fuente del Derecho imprevista por el constituyente, cuya ubicación en el ordenamiento se ha ido formando con el paso del tiempo.” (Sarmiento, 2011, p. 231). Así 
el principio de legalidad ha causado una lenta pero progresiva rebelión contra la autoridad del Derecho. Una rebelión protagonizada por una fuente alternativa, caracterizada por su falta de normatividad y desapego a la rigidez del principio de legalidad. Una fuente tan indeterminada en su contenido, que ha recibido el genérico y ambiguo nombre de soft law (Sarmiento, 2011, p. 223)

El soft law es entendido como un derecho no vinculante (Santaella, 2017) o "los actos o instrumentos jurídicos sin carácter obligatorio, pero incardinados, de una forma u otra, en el sistema de fuentes [...] con unos efectos jurídicos que no resultan del todo claros” (Santaella, 2017, p. 223). Aquí se encuentran las circulares, lineamientos, estándares, instrucciones, normas técnicas, códigos de buen gobierno, acuerdos, entre otros. Instrumentos sin regulación propia que están generando dificultades sobre su alcance en el sistema de fuentes derecho.

En la contratación estatal estos nuevos retos giran alrededor de las atribuciones e instrumentos de CCE, pues varias funciones parecen ser reglamentarias y se introducen competencias para expedir manuales, guías, entre otras actuaciones que no tienen una regulación sobre su fuerza vinculante, obligatoriedad y alcance.

Estos instrumentos resienten un sistema de fuentes caracterizado por la rigidez del principio de legalidad, una fuerte reserva legal y autonomía administrativa. Competitividad, eficiencia, mejores prácticas contractuales exigen una mayor ductilidad normativa. Sin embargo, se puede producir la "metamorfosis de las normas de derecho blando" (Sánchez, 2012, p. 87) y pasar de la informalidad a la ilegalidad, razón por la que es un imperativo analizar las funciones e instrumentos de esta entidad.

\section{CCE: Roles y funciones en la contratación estatal}

\subsection{Naturaleza y estructura orgánica de CCE}

El Gobierno Nacional en ejercicio de las facultades extraordinarias conferidas por la Ley 1444 de 2011, expidió el Decreto Ley 4170 de 2011 y creó CCE, con funciones de orientación, instrucción y otras de difícil calificación, que le permiten expedir instrumentos que se insertan en un ámbito 
tradicionalmente circunscrito a la autonomía administrativa o discrecionalidad de las entidades públicas, y que ha generado diversas calificaciones por la doctrina y jurisprudencia.

CCE se creó bajo la forma de Unidad Administrativa Especial como "entidad descentralizada de la Rama Ejecutiva del orden nacional, con personería jurídica, patrimonio propio y autonomía administrativa y financiera, adscrita al Departamento Nacional de Planeación” (art. 1), como consecuencia, "se sujetan al régimen jurídico contenido en la ley que las crea y en lo no previsto por ella, al de los establecimientos públicos” (art. 82, Ley 489 de 1998).

El Decreto Ley 4170 califica a CCE como un ente rector y le atribuye como propósito “desarrollar e impulsar políticas públicas y herramientas, orientadas a la organización y articulación, de los partícipes en los procesos de compras y contratación pública con el fin de lograr una mayor eficiencia, transparencia y optimización de los recursos del Estado" (art. 2) y se le asigna el rol de organismo técnico especializado para impulsar políticas, normas y unificar procesos en la contratación pública, preparar y suscribir los acuerdos marco de precios de que trata el artículo 2 de la Ley 1150 de 2007 (Considerandos Decreto 4170, 2011).

CCE en el ejercicio de sus competencias ha expedido múltiples instrumentos sin distinguir entre las entidades sometidas y excluidas del EGCAP, reiterando la normativa contractual $\mathrm{y}$, en algunos casos desarrollando aspectos no consagrados expresamente en la ley. La obligatoriedad de sus instrumentos, la competencia para expedirlos y su control judicial son muy controvertidos. Por eso es fundamental determinar su naturaleza como ente rector, dado que se asemeja mucho a otras instituciones como las agencias independientes, agencias de regulación, y/o comisiones de regulación, razón por la cual se precisarán estos conceptos.

Las agencias independientes tienen su origen en el derecho inglés, son entes reguladores que detentan gran autonomía en el seguimiento de una actividad económica, que afectan a los agentes del sector y ejercen un fuerte poder normativo en el sector económico (González, 2017, p. 65). Dentro de ellas, se encuentran múltiples instituciones que no pertenecen a las rama legislativa ni judicial y, por ello, se les suele calificar como "una verdadera descentralización del poder ejecutivo” (González, 2017, p. 65). 
Las comisiones de regulación en Colombia son originales y peculiares en muchos aspectos. Se trata de "unidades administrativas especiales, dotadas de autonomía administrativa, aunque están presididas por el ministro del ramo, y esto hace que las instrucciones presidenciales tengan peso decisivo en las decisiones e impiden que sean realmente independientes" (Marín, 2010, p. 409). Se pueden crear por vía constitucional (Banco de la República) o por vía legal (en los servicios públicos domiciliarios) y, por ende, para ser un ente regulador no se requiere del nomen iuris de comisión de regulación (Marín, 2010). Para González (2017) son sólo una manifestación del género de autoridades administrativas independientes.

En estos términos, se encuentran dos posiciones sobre la naturaleza de CCE como ente rector y organismo técnico especializado. La posición que considera que esta calificación es totalmente diferente de un ente regulador (Benavides y Duque, 2018) y la que la considera similar a una comisión de regulación (Marín, 2018).

Bajo la primera posición, los manuales, guías y demás parámetros deben ser entendidos como "meros instrumentos prácticos que permiten a los partícipes del sistema de contratación y compras públicas llevar a cabo sus tareas de mejor manera” (Santos, 2018, p. 346). CCE tendría la naturaleza de “ente pedagogo sobre mejores prácticas contractuales” (Martínez, 2018, p. 310 ), incluso para la Corte Constitucional no es un ente regulador puesto que "no se trata de un órgano con competencias reglamentarias, sino doctrinales y de fijación de políticas públicas” (Sentencia C-004/17).

Por el contrario, la segunda posición se justifica desde un punto de vista material en atención a las competencias asignadas. El Consejo de Estado en algunas providencias reconoce que cumple funciones de regulación administrativa y que conforme al numeral 10 del artículo 3 del Decreto 4170 tiene una "potestad reguladora que, en todo caso, debe ejercerse conforme a la Ley y ajustada a la potestad reglamentaria del Gobierno Nacional” (C.E. Auto del 14/08/2017, Exp. 58820). Incluso, defiende que "las funciones asignadas a la Agencia, si bien pueden comportar una facultad de regulación de la actividad contractual pública, ella debe ser ejercida con sometimiento al esquema jerárquico normativo del sistema jurídico" (C.E.Sentencia del 11/04/2019, Exp.52.055).

Sin embargo, el alto tribunal no se ha pronunciado de fondo sobre la naturaleza de CCE, pues en otras providencias niega que tenga funciones 
normativas (C.E. Auto del 13/10/2017, Exp. 57875) o atribuye la expedición de actos administrativos y reglamentos a su calidad de ente administrativo (C.E. Auto del 19/07/2018, Exp. 56307A); pero no a una cualificación especial como ente regulador o reglamentario.

En Colombia, se puede concluir que legalmente, bajo una interpretación estricta de las competencias, la existencia de un ente rector no es igual a un ente regulador. Sin embargo, la discusión por la naturaleza de CCE no se puede reducir a un criterio meramente formal, pues resulta más adecuada una noción material que no obedezca al nomen iuris; sino a los instrumentos que puede expedir por la habilitación legal; las funciones de dirección y coordinación de las compras públicas y sus características especiales, como la autonomía que reviste al ser un ente descentralizado y configurarse como unidad administrativa especial. En todo caso, el alcance de su naturaleza depende de sus funciones y competencias.

\subsection{Funciones de CCE: entre la coordinación y la potestad normativa}

Las funciones asignadas a CCE generan grandes discusiones y controversias dentro del marco jurídico vinculante en materia de contratación estatal: hard law, soft law, conceptos, lineamientos, instrucciones, circulares son sólo algunos conceptos sobre los que gira la discusión. Por esto, se identificarán sus funciones, precisando que su alcance depende de la naturaleza de esta entidad como ente rector dedicado a la coordinación y/o creación normativa.

El Decreto Ley 4170 de 2011 que creó a CCE establece sus competencias en el artículo 3, tales como: la formulación de políticas, racionalización normativa, desarrollo y difusión, coordinación, elaboración de estudios, diagnósticos y estadísticas, absolución de consultas, expedición de circulares, apoyo al Gobierno en las negociaciones internacionales, apoyo a los oferentes y a las entidades territoriales; diseñar, organizar y celebrar acuerdos marco de precios.

Los órganos superiores de dirección y administración de esta entidad son el Director General y el Consejo Directivo. Al primero, se le asignan funciones de formulación, aprobación, fijación y diseño de políticas, parámetros y metodologías para la normalización de procesos y procedimientos de contratación (Decreto Ley 4170, 2011, art. 7). El segundo tiene funciones 
similares y la competencia para "expedir circulares externas en materia de compras y contratación pública” (Decreto Ley 4170, 2011, art. 10 núm. 7 y 13). Además, dentro de las funciones se destaca la de "desarrollar e implementar estándares y documentos tipo para las diferentes etapas de la gestión contractual pública” (Decreto Ley 4170, 2011, art. 11.12).

El Decreto 1082 de 2015, único reglamentario del sector administrativo de planeación nacional le prescribe funciones para establecer lineamientos, diseñar e implementar los instrumentos para la elaboración del Plan Anual de Adquisiciones (art. 2.2.1.2.5.1.), señalar los lineamientos que deben cumplir los manuales de contratación (art. 2.2.1.2.5.3) y se le otorga competencia para adoptar múltiples instrumentos, estándares y documentos tipos, en los siguientes términos:

Artículo 2.2.1.2.5.2. (Decreto 1510 de 2013, artículo 159) Estándares y documentos tipo. Sin perjuicio de la función permanente que el DecretoLey 4170 de 2011 le asigna, Colombia Compra Eficiente debe diseñar e implementar los siguientes instrumentos estandarizados y especializados por tipo de obra, bien o servicio a contratar, así como cualquier otro manual o guía que se estime necesario o sea solicitado por los partícipes de la contratación pública:

1. Manuales para el uso de los Acuerdos Marco de Precios.

2. Manuales y guías para: (a) la identificación y cobertura del Riesgo; (b) la determinación de la Capacidad Residual para los contratos de obra pública dependiendo del valor de los mismos; (c) la elaboración y actualización del Plan Anual de Adquisiciones; y (d) el uso del Clasificador de Bienes y Servicios.

3. Pliegos de condiciones tipo para la contratación.

4. Minutas tipo de contratos.

Sobre estas competencias se pronunció el Consejo de Estado en la Sentencia del 11 de abril de 2019 (Exp. 52.055), declaró la nulidad del literal a) del numeral 2 y los numerales 3 y 4 , por encontrar un traspaso indebido de la facultad reglamentaria del Presidente de la República y estableció los parámetros para analizar las funciones otorgadas a CCE.

En atención a las funciones de CCE se evidencia que con los instrumentos que puede expedir, se busca coordinar la actividad contractual, orientar a las entidades públicas y a los partícipes en la contratación estatal. En principio ninguna de las funciones de esta entidad implica una potestad normativa 
expresa, ya que no se le asigna tareas con el verbo reglamentar o regular. Sin embargo, algunas funciones reflejan materialmente una competencia normativa, cuando tiene la función de expedir circulares externas en la contratación pública y por las competencias del artículo 2.2.1.2.5.2. del Decreto 1082 de 2015 (Decreto 1082, 2015, art. 2.2.1.2.5.2), aspectos que se precisarán más adelante.

Las circulares y los otros instrumentos innovadores en la contratación pública como manuales, lineamientos, guías, entre otros, evidencian la creación de auténticas restricciones a la autonomía administrativa de las entidades públicas, que no provienen del legislador y que exigen revisar los instrumentos de CCE, pues aunque varios de ellos parecen ser orientaciones de tipo político, su pretensión de orientación, sistematización y unificación de prácticas evidencian un carácter vinculante que impulsa su análisis.

En la doctrina se advierte "la delgada línea que existe entre la atribución funcional a este organismo y el alcance de la potestad reglamentaria” (Safar, 2017, p. 161). Los expertos en la materia coinciden en que no es posible calificar sus funciones en abstracto, dado que se requiere un estudio riguroso de cada una de sus competencias (Marín, Suárez, Duque, Gil y Benavides, 2018). Incluso CCE y los órganos de control fiscal reiteran su status legal como ente rector; pero diferencian sus atribuciones en atención a sus instrumentos -como se analizará más adelante (2018)-. Esta inquietud fue objeto de estudio por el Consejo de Estado bajo el prisma del poder reglamentario del Presidente de la República en la Sentencia del 11 de abril de 2019 frente a los instrumentos que se impulsaron con el Decreto 1082 de 2015 (Decreto 1082, 2015), donde reitera el carácter técnico especializado de CCE e indica que no todos sus instrumentos son vinculantes (Exp. 52.055).

Por exceder el alcance de este trabajo, se deja para la posteridad un estudio especializado de sus funciones y se analizan sus generalidades a partir de los roles que asume CCE. Frente a estos surgen dos posiciones: i) sus funciones sólo son de coordinación, y ii) sus funciones son de coordinación y de creación normativa. Bajo la primera posición, se afirma que, debido a su configuración orgánica, sus funciones son de ejecución de la ley y de reglamentación mediante la estructuración de políticas públicas, por cumplir funciones que le corresponderían al Departamento Nacional de Planeación y "estudiar la materia de la contratación pública para informar de la misma a la cabeza de su sector (upstream),” (Safar, 2017, p. 165). En este sentido, Santos afirma que 
CCE no es un órgano creador de normas -ni regulador- en materia contractual; sino que sólo puede proponerlas y "crear instrumentos que permitan la mejor aplicación de las normas sobre contratación y compras públicas vigentes” (Santos, 2018, p. 346).

Con relación a este poder de instrucción se reconoce que CCE, como unidad administrativa, no es superior jerárquica o funcional y no tiene funciones de control o vigilancia sobre la actividad contractual, ya que "no posee competencias decisorias respecto a la forma que debe contratar cada entidad del Estado” (Martínez, 2018, p. 311). Su rol de coordinación se traduce en una competencia enteramente sectorial y transversal y "cuando emplea la aludida función estamos ante verdaderas guías que buscan definir mejores prácticas en la contratación estatal o derecho blando” (Martínez, 2018, p. 311).

Incluso la Corte Constitucional y el Consejo de Estado han señalado que su rol es de dirección de la gestión contractual. Se niega expresa y tácitamente la existencia de competencias normativas y la suplantación de funciones del legislador, otra entidad o autoridad (C-004 de 2017 y Auto del 13/10/2017, Exp. 57875), hasta el punto de declararse la nulidad de algunas competencias otorgadas por el artículo 2.2.1.2.5.2. del Decreto 1082 de 2015 (Decreto 1082, 2015, art. 2.2.1.2.5.2) por presentarse un traslado de las competencias reglamentarias del Presidente de la República y precisarse que: "no podría considerarse que con el Decreto-Ley mencionado se distribuyeron las competencias reglamentarias entre el Presidente de la República y la nueva agencia, asignando a esta última todo aquello relativo a la contratación del Estado” (Sentencia del 11/04/2019, Exp. 52.055).

La segunda posición tiene como punto de partida el reconocimiento de que CCE tiene unas funciones de orientación, coordinación y de instrucción de la contratación estatal; pero también potestades normativas como elemento implícito de su función de coordinación o como función autónoma. En el primer sentido, se reconoce el poder de instrucción mediante las circulares externas que según el Consejo de Estado, implican el ejercicio de una potestad normativa (Suárez, Duque, Marín, Gil y Benavides, 2018). En consecuencia, las funciones de CCE implican construir políticas públicas y ejecutarlas por medio de los "instrumentos jurídicos correspondientes (actos administrativos de carácter general)” (Safar, 2017, p 165).

Esta competencia es muy reducida en comparación con una consagración expresa, posición que asume el Consejo de Estado cuando advierte que CCE 
ejerce una competencia de orientación o coordinación toda vez que tiene a su cargo la formulación de políticas públicas, y según las voces del numeral 10 del artículo 3 del Decreto 4170 de 2011 tiene una "potestad reguladora que, en todo caso, debe ejercerse conforme a la Ley y ajustada a la potestad reglamentaria del Gobierno Nacional” (C.E. Auto del 14/08/2017, Exp. 58820). Incluso esta posición es la que se defiende en atención a la competencia para expedir sus instrumentos y la naturaleza de los mismos (C.E. Auto del 19/07/2018, Exp. 56307A), según obedezcan a la noción material de actos administrativos generales.

Al respecto, el Consejo de Estado en la Sentencia del 11 de abril de 2019 precisó que “con el Decreto-Ley 4170 de 2011 el legislador extraordinario no quiso modificar -como en efecto no lo hizo- el esquema de producción normativa establecido en la Constitución Política”. Por tanto, concluyó que si bien las funciones asignadas a CCE "pueden comportar una facultad de regulación de la actividad contractual pública, ella debe ser ejercida con sometimiento al esquema jerárquico normativo del sistema jurídico” (Exp. 52.055). De esta manera, reconoce una función normativa, pero no autónoma, de carácter reglamentario, que cualifica como de segundo o tercer orden para indicar que se debe ejercer conforme a la potestad reglamentaria del Presidente de la República y que debe respetar los ámbitos de autonomía de la voluntad de las entidades públicas protegidos por el legislador.

Bajo esta segunda posición, que se defiende en este texto, se advierte la similitud con entidades como las comisiones de regulación, agencias reguladoras o agencias independientes, puesto que al respetar el principio de juridicidad, la fuerte reserva legal y el ámbito de protección de la autonomía administrativa, las potestades normativas pueden provenir de la constitución o la ley. La estructura orgánica implica independencia del poder ejecutivo, sus instrumentos se resguardan en un criterio técnico o de especialización. Sin embargo, la tenue referencia legal en la materia exige en el caso concreto precisar sus instrumentos, al advertir desde ya que su existencia es independiente de la legalidad de su competencia. 


\section{Naturaleza, fuerza vinculante y obligatoriedad de los instrumentos expedidos por CCE}

\subsection{Instrumentos expedidos por CCE}

Con relación a sus instrumentos, hasta el 15 de julio de 2018 había expedido 25 circulares externas, sustituidas por la Circular Externa Única del 16 de julio de 2018 y 26 instrumentos (manuales, guías, lineamientos y otras figuras), que se relacionan para identificar las materias de intervención y el alcance de sus competencias, tal como se muestra en los siguientes cuadros:

Cuadro No.1. Instrumentos de CCE.

\begin{tabular}{|l|l|}
\hline \multicolumn{2}{|l|}{ Circulares } \\
\hline No & Tema \\
\hline 1 & $\begin{array}{l}\text { Publicidad en el } \\
\text { Secop }\end{array}$ \\
\hline 20 & $\begin{array}{l}\text { Publicidad en } \\
\text { el SECOP para } \\
\text { sistemas de } \\
\text { contratación en } \\
\text { línea de EICES, } \\
\text { SEM y ESP }\end{array}$ \\
\hline 2 & $\begin{array}{l}\text { Plan Anual de } \\
\text { Adquisiciones }\end{array}$ \\
\hline $3,18,19$ & $\begin{array}{l}\text { Ley de Garantías } \\
\text { Electorales }\end{array}$ \\
\hline 24 & $\begin{array}{l}\text { Identificación y } \\
\text { Cobertura del } \\
\text { Riesgo }\end{array}$ \\
\hline 5,11 y 14 & $\begin{array}{l}\text { Capacidad } \\
\text { Residual }\end{array}$ \\
\hline
\end{tabular}

\begin{tabular}{|c|c|c|}
\hline \multicolumn{3}{|c|}{ Otros instrumentos } \\
\hline Expedición & Clase & Tema \\
\hline 20180717 & G & $\begin{array}{l}\text { Compras } \\
\text { socialmente } \\
\text { responsables }\end{array}$ \\
\hline 20180717 & G & $\begin{array}{l}\text { Compras } \\
\text { sostenibles con el } \\
\text { medio ambiente }\end{array}$ \\
\hline 20180607 & G & $\begin{array}{l}\text { Competencia en las } \\
\text { compras públicas }\end{array}$ \\
\hline 20180205 & G & $\begin{array}{l}\text { Circulación de } \\
\text { facturas emitidas } \\
\text { en desarrollo de un } \\
\text { contrato }\end{array}$ \\
\hline 20170731 & G & $\begin{array}{l}\text { Ofertas } \\
\text { artificialmente } \\
\text { bajas en Procesos } \\
\text { de Contratación }\end{array}$ \\
\hline 20170728 & G & $\begin{array}{l}\text { Participación } \\
\text { de proveedores } \\
\text { extranjeros }\end{array}$ \\
\hline 20161118 & G & $\begin{array}{l}\text { Entidades Estatales } \\
\text { con régimen } \\
\text { especial de } \\
\text { contratación }\end{array}$ \\
\hline
\end{tabular}




\begin{tabular}{|l|l|}
\hline 6 & $\begin{array}{l}\text { Contratación } \\
\text { de actividades } \\
\text { de ciencia, } \\
\text { tecnología } \\
\text { innovación }\end{array}$ \\
\hline 7 & $\begin{array}{l}\text { Incentivos } \\
\text { a los bienes } \\
\text { agropecuarios } \\
\text { nacionales }\end{array}$ \\
\hline 8 & $\begin{array}{l}\text { Manual para la } \\
\text { Identificación y } \\
\text { Cobertura del } \\
\text { Riesgo }\end{array}$ \\
\hline 9 & $\begin{array}{l}\text { Lineamientos } \\
\text { Generales para } \\
\text { la Expedición } \\
\text { de Manuales de } \\
\text { Contratación }\end{array}$ \\
\hline 10 & $\begin{array}{l}\text { Expedición de } \\
\text { manuales y guías }\end{array}$ \\
\hline 12 & $\begin{array}{l}\text { Clasificador } \\
\text { de Bienes y } \\
\text { Servicios }\end{array}$ \\
\hline 13 & $\begin{array}{l}\text { Subsanabilidad } \\
\text { de requisitos } \\
\text { y documentos } \\
\text { que no otorgan } \\
\text { puntaje } \\
\text { documentos } \\
\text { Contratación }\end{array}$ \\
\hline $\begin{array}{l}\text { Documentos tipo } \\
\text { contratos plan }\end{array}$ \\
habilitantes \\
Manual de \\
\hline 16
\end{tabular}

\begin{tabular}{|c|c|c|}
\hline 20161020 & G & $\begin{array}{l}\text { Supervisión e } \\
\text { interventoría }\end{array}$ \\
\hline 20160726 & G & Obra pública \\
\hline 20160623 & G & $\begin{array}{l}\text { Asuntos } \\
\text { corporativos } \\
\text { en Procesos de } \\
\text { Contratación }\end{array}$ \\
\hline 20160322 & G & $\begin{array}{l}\text { Liquidación } \\
\text { contratos estatales }\end{array}$ \\
\hline 20160116 & $\mathrm{G}^{*}$ & $\begin{array}{l}\text { Contratación con } \\
\text { entidades sin } \\
\text { ánimo de lucro } \\
\text { y de reconocida } \\
\text { idoneidad }\end{array}$ \\
\hline 20141215 & G & $\begin{array}{l}\text { Garantías en } \\
\text { Procesos de } \\
\text { Contratación }\end{array}$ \\
\hline 20141215 & M & $\begin{array}{l}\text { Incentivos en } \\
\text { Procesos de } \\
\text { Contratación }\end{array}$ \\
\hline 20140606 & - & Matriz de riesgos \\
\hline 20140425 & $\mathrm{G}^{*}$ & $\begin{array}{l}\text { Capacidad Residual } \\
\text { del proponente en } \\
\text { contratos de obra } \\
\text { pública }\end{array}$ \\
\hline 20140425 & - & $\begin{array}{l}\text { Aplicativo para } \\
\text { calcular la } \\
\text { capacidad residual }\end{array}$ \\
\hline 20140117 & G & $\begin{array}{l}\text { Manejo de anticipos } \\
\text { mediante contrato } \\
\text { de fiducia mercantil } \\
\text { irrevocable }\end{array}$ \\
\hline 20140117 & M & $\begin{array}{l}\text { Operación } \\
\text { Secundaria de } \\
\text { los Instrumentos } \\
\text { de Agregación de } \\
\text { Demanda }\end{array}$ \\
\hline
\end{tabular}




\begin{tabular}{|l|l|}
\hline 21 & Uso del SECOP II \\
\hline 22 & $\begin{array}{l}\text { Acreditación de } \\
\text { la formación } \\
\text { académica }\end{array}$ \\
\hline 23 & $\begin{array}{l}\text { Calidad y } \\
\text { oportunidad de } \\
\text { la información } \\
\text { disponible en el } \\
\text { SECOP }\end{array}$ \\
\hline 25 & $\begin{array}{l}\text { Guía para la } \\
\text { contratación } \\
\text { con entidades } \\
\text { privadas sin } \\
\text { ánimo de lucro } \\
\text { y de reconocida } \\
\text { idoneidad }\end{array}$ \\
\hline
\end{tabular}

\begin{tabular}{|c|c|c|}
\hline 20131227 & G & $\begin{array}{l}\text { Elaboración de } \\
\text { Estudios de Sector }\end{array}$ \\
\hline 20131226 & $\mathrm{~L}^{*}$ & $\begin{array}{l}\text { Lineamientos } \\
\text { generales para } \\
\text { la expedición } \\
\text { de manuales de } \\
\text { contratación }\end{array}$ \\
\hline 20131223 & M & $\begin{array}{l}\text { Requisitos } \\
\text { habilitantes }\end{array}$ \\
\hline 20131127 & M & $\begin{array}{l}\text { Acuerdos } \\
\text { Comerciales }\end{array}$ \\
\hline 20131126 & M & $\begin{array}{l}\text { Modalidad de } \\
\text { selección Mínima } \\
\text { Cuantía }\end{array}$ \\
\hline 20130923 & M & $\begin{array}{l}\text { Identificación } \\
\text { y cobertura del } \\
\text { Riesgo }\end{array}$ \\
\hline 20130222 & G & $\begin{array}{l}\text { Elaboración del } \\
\text { Plan Anual de } \\
\text { Adquisiciones }\end{array}$ \\
\hline 20130221 & G & Acuerdos Marco \\
\hline 20130220 & G & $\begin{array}{l}\text { Codificación de } \\
\text { Bienes y Servicios }\end{array}$ \\
\hline
\end{tabular}

La cantidad de instrumentos expedidos por CCE es alarmante a la luz de un estatuto de principios como el EGCAP y el rechazo a la excesiva reglamentación de la materia. En materia contractual ya no estamos ante un legislador motorizado; sino ante una administración motorizada o una CCE motorizada, en cuanto productor de lineamientos, estándares, directrices, entre otros instrumentos; frente a los cuales no existe una definición legal ni regulación de su régimen jurídico. 
Sin embargo, a partir de un análisis inductivo se encuentra que estos instrumentos concretan, por un lado, principios de la contratación pública aplicables por todas las entidades públicas, como la publicidad y el manejo presupuestal; se ocupa de figuras propias del EGCAP como las garantías, los acuerdos marco de precios, la capacidad residual y liquidación del contrato estatal. Figuras que en prima facie no son aplicables a las entidades excluidas del EGCAP. Por otro, se ocupa de temas generales donde no se distingue el régimen contractual.

Algunas guías afirman que su propósito "es difundir normas, reglas, procedimientos y mejores prácticas sobre temas puntuales del sistema." (CCE, 2018a, p. 3); otras: "identificar las principales características de las ofertas artificialmente bajas presentadas en los Procesos de Contratación y dar pautas para su manejo, en línea con las mejores prácticas internacionales en la materia." (CCE, 2017) y "definir lineamientos y orientar a las Entidades Estatales en las características de cada una de las clases de garantía” en los Procesos de Contratación sujetos al Decreto 1082 de 2015 (CCE, 2017, p. 3).

En varias guías y manuales se advierte la remisión constante entre guías y circulares (Guía de Participación de proveedores extranjeros). Por ejemplo, la Guía del contrato de obra pública hace obligatorias las guías de estudio del sector y cobertura del riesgo (CCE, 2016) y en la calidad adoptan criterios internacionales como un "deben tener en cuenta" (CCE, 2016, p. 13). Наy guías con ciertas particularidades dentro del sistema de fuentes, puesto que la justificación de la Guía de Contratación con entidades sin ánimo de lucro y de reconocida idoneidad es que el Decreto 092 de 2017 condicionó su aplicación a la expedición de esta guía por parte de CCE.

CCE cambia los principios de la contratación estatal por los principios del sistema de compras públicas. Reglas como el uso del Clasificador de bienes y servicios exceden lo previsto en la normativa especial de las entidades excluidas del EGCAP (Guía para las Entidades Estatales con régimen especial de contratación), hace vinculante los lineamientos para expedir los manuales de contratación, establece la sujeción a varias normas del EGCAP y obligaciones del Decreto 1082. Incluso afirma que: "deben aplicar las circulares y los manuales y guías correspondientes de acuerdo con la naturaleza de su régimen”. Estas se enlistan así: manuales sobre riesgos, acuerdos comerciales e incentivos en la contratación, guías de codificación de bienes y servicios con el clasificador de bienes y servicios de las Naciones Unidas- The United Nations Standard Products and Services Code (UNSPSC), plan anual de adquisiciones, 
estudios del sector, acuerdos marco de precios y manejo de anticipos.

En efecto, frente a estos instrumentos surge la inquietud por su fuerza vinculante, pues varios de ellos no se limitan a citar las normas superiores ni se redactan como sugerencias de políticas y prácticas públicas carentes de obligatoriedad. Varios de ellos innovan dentro del ordenamiento jurídico, se redactan en términos impositivos o en términos de deber ser y se adoptan con la expedición de circulares que reiteran su carácter vinculante. En consecuencia, surge la pregunta por el carácter vinculante y obligatorio de estos estándares: ¿se trata de actos administrativos?, ¿cómo se controlan?, ¿cuáles son las consecuencias de no seguir los parámetros previstos por CCE?

\subsection{Naturaleza y fuerza vinculante}

Los instrumentos expedidos por CCE representan una intromisión a la relación tradicional en el sistema de fuentes de derecho administrativo entre la reserva legal y la autonomía administrativa, interferida excepcionalmente por la potestad reglamentaria del Presidente de la República. La naturaleza de estos instrumentos no ha sido un asunto pacifico, razón que justifica su identificación y la determinación de su fuerza vinculante u obligatoria a partir de la doctrina, la jurisprudencia del Consejo de Estado -especialmente la Sentencia del 11 de abril de 2019-, la posición de CCE y las autoridades encargadas de la orientación y vigilancia de la gestión contractual.

Al respecto, la doctrina advierte la existencia de un "doble nivel, vinculante y no vinculante, de la reglamentación en la contratación pública” (Santaella, 2017, p.783), porque mientras el Consejo de Estado ha admitido y decretado algunas medidas cautelares sobre estos instrumentos (Auto del 29/03/2017, Exp. 56307); desde un sector de la doctrina se afirma que no pueden ser entendidos como verdaderas expresiones normativas, sino simplemente como instrumentos o herramientas técnicas de regulación (Santos, 2018). Incluso hoy la discusión se orienta con categorías propias del derecho internacional como el hard law -constitución, ley, reglamento identificado formalmente- y el soft law -derecho blando, vinculante pero no coercitivo-.

Para determinar su fuerza vinculante u obligatoria en el sistema de fuentes de derecho se realizó derechos de petición a CCE y a los órganos de control fiscal como la Contraloría General de la República, Contraloría 
de Bogotá y de Medellín, igualmente, a los órganos de control disciplinario como la Procuraduría General de la Nación. Además se tiene la posición de los profesores Fabián Marín, José Luis Benavides y Juan David Osorio, David Suárez, Jorge Iván Duque y Willington Gil, y la posición del Consejo de Estado, acogida en la Sentencia del 11 de abril de 2019 (Exp. 52.055). Conforme a lo anterior, se identifican tres posiciones sobre la fuerza vinculante de estos instrumentos: las primeras dos permiten identificar una norma del hard law desde un criterio material o un criterio formal desde la teoría del derecho (Guastini, 1999), y la tercera, que permite identificar estos instrumentos como normas del soft law.

\subsubsection{Posición material derivada del contenido genuinamente normativo}

Para Marín, Suárez y Duque no puede decirse en abstracto que los instrumentos de CCE son vinculantes, porque esto depende de las competencias legales conferidas en el Decreto 4170 de 2011 y del contenido material de estos instrumentos (Marín, 2018; Suárez, 2018; Duque, 2018). Marín considera que el problema se encuentra en la incorporación de un ente regulador y los problemas de armonización con el resto del ordenamiento jurídico, en tanto, considera que sus instrumentos vinculan en razón de su competencia (2018). Además, ambos expertos coinciden en un criterio material derivado del contenido del instrumento y será acto administrativo si contienen una manifestación de la voluntad unilateral del Estado en ejercicio de funciones administrativa que produzca efectos jurídicos.

Esta posición está en consonancia con el Auto del día 19 de julio de 2018 del Consejo de Estado, que al resolver un recurso de súplica frente a la decisión de la Sección Tercera de suspender provisionalmente uno de los instrumentos de CCE (Exp. 56307A), precisó que las funciones de CCE se materializaban necesariamente mediante la expedición de actos administrativos, así: "la materialización de las funciones de CCE en actos administrativos -entendidos como decisiones unilaterales de la Administración que generan efectos jurídicos- es igualmente ajustada a la ley, en consideración a la naturaleza jurídica de la entidad”.

Justificó esta conclusión por la naturaleza de la entidad como persona jurídica pública, por pertenecer a la rama ejecutiva y por su categoría de ente rector de la contratación pública. Sin embargo, advirtió que una cosa distinta es que en estos instrumentos se evidencie "el desbordamiento de las competencias expresamente atribuidas por el legislador o la infracción del ordenamiento 
jurídico”. Esta noción material se consolidó con la Sentencia del 11 de abril de 2019, donde el Consejo de Estado tras analizar la naturaleza de los manuales expedidos por CCE -análisis que se debe extender a sus otros instrumentosprecisó que las funciones de la entidad pueden producir normas reglamentarias de segundo o tercer grado y que "no es el nombre que recibe el que le otorga la naturaleza de acto administrativo, sino su contenido reglamentario o normativo de obligatoria aplicación, y ello es predicable, incluso, de los manuales expedidos por las distintas autoridades.” (Exp. 52.055).

En todo caso, la naturaleza de tales instrumentos depende del contenido de los mismos y su adecuación a la noción de acto administrativo en sentido material, que podrá revestir el carácter de reglamento si es general y tiene vocación de permanencia en el tiempo.

\subsubsection{Posición formal o derivada del nomen iuris, procedimiento para su expedición y la competencia del órgano administrativo}

Para Osorio, Director jurídico de CCE, las circulares son obligatorias, las actuaciones expedidas en ejercicio de la función consultiva son conceptos en los términos del CPACA, las guías y manuales no son normas; sino lineamientos siendo finalmente la entidad la que determina los criterios a adoptar (2018). CCE en respuesta a derecho de petición afirma que si bien los manuales, guías y documentos tipo pueden considerarse actos administrativos, precisa que sólo obligan aquellos que tengan un respaldo normativo sobre su obligatoriedad, así:

Los Manuales y Guías establecidos en los numerales 1 y 2 del artículo 2.2.1.2.5.2. y en el artículo 2.2.1.2.5.3 del Decreto 1082 de 2015 son de obligatorio cumplimiento por disposición del mismo Decreto 1082 de 2015. Los demás manuales y guías son herramientas de orientación para los partícipes del Sistema de Compra Pública en Procesos de Contratación.

Además de lo anterior, son de imperativo cumplimiento las normas que remitan y expresen en su contenido la obligatoriedad de los documentos o instrumentos elaborados por Colombia Compra Eficiente. (CCE, 2018, p. 1)

Así, CCE señala que es obligatoria la guía que desarrolla el Decreto 092 de 2017 conforme al numeral 16.3 de la Circular Externa Única y que conforme al Decreto 1082 de 2015 "los Lineamientos generales para la expedición de 
manuales de contratación de Colombia Compra Eficiente son obligatorios.” (CCE, 2018, p. 4).

Los criterios adoptados por CCE son formales, aunque un poco cuestionables, no obedecen al nomen iuris, ni procedimiento para su expedición, ni propiamente a su competencia. Los entes de control y varios doctrinantes aplican el criterio formal del nomen iuris solo frente a las circulares externas; pero advirtiéndose que esta posición no es unánime. Para la Contraloría General de Medellín (2018) los instrumentos de CCE son "herramientas de orientación” que incorporan buenas prácticas y procedimientos que facilitan los procesos contractuales, salvo los Manuales y Guías establecidos en los numerales 1 y 2 del artículo 2.2.1.2.5.2. y en el artículo 2.2.1.2.5.3 del Decreto 1082 de 2015 que son de obligatorio cumplimiento por disposición del mismo Decreto 1082 de 2015.

La Contraloría General de Bogotá, en cada una de sus direcciones y dependencias, dio respuesta a este interrogante señalando que "sí tratamos como actos administrativos los lineamientos, manuales y guías debido a que son obligatorios para todas las Entidades Estatales, entre estas, este ente de control y en cada auditoria aplicamos dichos lineamientos, manuales y guías a la hora de analizar cada uno de los contratos a auditar" (Dirección Sector Gestión Jurídica, 2018, p. 2). Sin embargo, la subdirección de contratación señala lo mismo que la Contraloría General de Medellín (2018)

Con relación a las circulares externas existe consenso institucional ya que el Consejo de Estado las reconoce como actos administrativos generales y, por tanto, gozan de la presunción de legalidad -obligatoriedad- y de carácter ejecutorio, siempre que tengan la potencialidad de producir efectos jurídicos (CCE, 2018; Contraloría General de Medellín, 2018). En el mismo sentido, piensan De Vivero (2013) y Safar (2017); pero sólo desde la expedición del CPACA y del nuevo rol de las circulares como actos administrativos.

Bajo esta posición, se concluye que no se reconoce valor normativo a los demás instrumentos de CCE que no tienen el nombre de circular, ni siquiera se acoge el criterio de procedimiento para determinar su naturaleza y, respecto de la competencia, en atención a lo prescrito por el Consejo de Estado en el auto del 19 de julio de 2018, no se debe confundir la naturaleza del instrumento —acto administrativo — con su legalidad, pues son aspectos independientes. 


\subsection{Los instrumentos de CCE en el sistema de fuentes: la regulación no vinculante en el derecho administrativo (soft law)}

Si se califican los instrumentos de CCE, que no sean hard law, como manifestaciones del soft law, son mandatos de optimización con una proposición prescriptiva que pretende ser cumplida solo en grado y reviste la estructura de reglas y principios (Sarmiento, 2011), pues se trata de "instrumentos laxos de regulación, en oposición a las tradicionales proposiciones prescriptivas y sus correspondientes sanciones" (CCE, 2011, p. 264).

Benavides señala que estos instrumentos evidencian las dificultades de la influencia internacional que rompe con las dinámicas del derecho fundado en la estructura piramidal del sistema de fuentes, para dar paso a nuevas figuras del derecho blando (2018). En este sentido, se encuentra un reconocimiento tácito de instrumentos no vinculantes en Marín (2018), Duque (2018), De Vivero (2013), CCE (2018) y los órganos de control (2018), e incluso un reconocimiento expreso de que se trata del derecho blando o soft law por parte de Gil (2018), Martínez(2018), Santos (2018), Safar (2017), Santaella (2017) y Benavides (2018).

Gil considera que, salvo las circulares, los instrumentos de CCE son simples apreciaciones y conceptos de política pública en materia de compra pública (2018); mientras para Safar son "instrumentos de gerencia que permiten mayor trasparencia y eficacia en las relaciones de contratación” (2017, p.171) y salvo en los acuerdos marco de precios, los demás son solo una orientación que entra al campo del derecho blando (Safar, 2017, p. 176).

Santaella (2017) considera que al carecer de un fundamento legal expreso que les reconozca carácter vinculante y ser expedidas en ejercicio de una función orientadora de las mejores prácticas, están desprovistos de efectos jurídicos. Para Benavides (2018) y Santos (2018) como CCE no es un ente creador de normas, sus instrumentos, no solo no tienen un carácter obligatorio, sino que ni siquiera puede reconocerse un contenido normativo y su control judicial sólo es la aplicación del principio de que no hay actuaciones exentas de control judicial.

Con todo, tal como afirma Martínez, aunque algunos instrumentos hacen parte del derecho blando, su incorporación al orden jurídico colombiano hace que sea "natural el seguimiento a sus lineamientos, de modo que sus efectos así sean indirectos, son incontrovertibles; condicionan la actividad estatal y la 
de sus partícipes.” (2018, p. 312), recortan la discrecionalidad administrativa y, por ende, tienen vocación normativa (Martínez, 2018); solo que desde el soft law.

Sobre la discusión del soft law de CCE, debe tenerse en cuenta que el Consejo de Estado en la Sentencia del 11 de abril de 2019 acogió un criterio material para determinar la fuerza vinculante de los instrumentos de CCE y calificarlos como hard law. En tal sentido, declaró la nulidad de los numerales 3 y 4 del artículo 159 del Decreto 1510 de 2013 (compilado en el Decreto 1082, 2015, art. 2.2.1.2.5.2.), con relación a la expedición de pliegos de condiciones tipo y minutas tipo de contrato, por considerar que CCE no tenía competencia para su expedición; pero al analizar estos instrumentos también precisó que "no podrán servir de referencia vinculante a las entidades públicas respectivas”, de modo que, les otorga la naturaleza de orientaciones (Exp. 52.055).

Sólo se realiza una salvedad frente a los pliegos tipos previstos en el parágrafo 3 del artículo 2 de la Ley 1150 de 2007, por existir una disposición legal que establece la competencia, incluyéndolos, por lo tanto, dentro del hard law. Este criterio también debe extenderse al artículo 4 de la Ley 1882 de 2018 que adopta los pliegos tipo para los procesos de selección de obras públicas, interventoría para las obras públicas, interventoría para consultoría de estudios y diseños para obras públicas y consultoría en ingeniería para obras.

Con fundamento en estas tres posiciones es claro que no hay una categoría unívoca frente a los instrumentos expedidos por CCE. Solo frente a las circulares externas existe un consenso sobre su carácter vinculante, sobre los demás tampoco se puede afirmar en abstracto que son herramientas jurídicas no vinculantes, porque su carácter normativo dependerá de criterios formales -algunos cuestionables- y materiales adoptados por el alto tribunal de lo contencioso administrativo. De modo que, solo en el caso concreto y en ausencia de un criterio que le otorgue un carácter normativo y vinculante como actos administrativos, entrarán al campo del soft law. Ese derecho blando que se reconoce en la doctrina bajo la estructura de los principios como mandatos de optimización. 


\section{A modo de conclusión: Las alteraciones del sistema de fuentes de derecho administrativo en el marco de la aparente inconstitucionalidad y/o ilegalidad a la introducción del soft law por CCE}

Una gran paradoja rodea las funciones de CCE y sus instrumentos. Por un lado, se condiciona la naturaleza de estos últimos a las competencias expresamente fijadas en la ley -respeto por la reserva legal-; de otro lado, se valora sus funciones en razón de sus actuaciones, encontrándose como único punto firme la cualificación de CCE como ente rector y especializado en materia contractual.

Los instrumentos de CCE no son un consejo o un dato carente de efectos jurídicos, son auténticas normas que se insertan en el sistema de fuentes de derecho, en cuanto imponen pautas que se “deben” seguir, acoger, desarrollar y observar. Algunas son de hard law, cuando desde un criterio material ostentan la calidad de acto administrativo o reglamento. Otras son del novedoso soft law. Un solo efecto jurídico irrefutable permite llegar a esta conclusión: la restricción de la discrecionalidad administrativa, libertad contractual 0 autonomía administrativa.

La ausencia de competencia para su expedición no afecta su existencia y obligatoriedad, cuando ostenten el atributo de presunción de legalidad (Consejo de Estado, Auto del 19/07/2018, Exp. 56307A). Sin embargo, debe ponerse atención a la competencia -legal, reglamentaria, exclusiva, indelegable, etc.- y procedimiento para su expedición, su alcance, consecuencias y control, pues como advierte Martínez: "este instrumento no puede situarse como un derecho subrepticio que solo sale a luz cuando se adopta una decisión en concreto" (2018, p. 313).

El control es un imperativo pues en la gestión pública existe un mayor protagonismo y expansión de los instrumentos laxos, blandos o flexibles de regulación, puesto que "el soft law se convierte en una de las piezas elementales de las nuevas políticas públicas, en la medida en que garantiza los tres rasgos configuradores que antes hemos descrito: ductilidad, temporalidad y adaptabilidad” (Sarmiento, 2011, p. 265), para ceñirse a las técnicas de ejecución de políticas públicas. 
En consecuencia, es necesario reconocer su valor normativo en el sistema de fuentes, pues como señala Sarmiento "Sólo desde la existencia de una función normativa cabe aceptar la adopción y propagación de soft law, y esta función, como se defendió con anterioridad, pasa por la generación de un deber de interpretación del hard law de conformidad con el soft law" (2011, p. 267). Hoy este efecto se impone; pero no se reconoce expresamente. Aquí reside el reto de su legitimidad y legalidad. La ausencia de una regulación de sus efectos no implica que no los tenga.

En estos términos, CCE asume el rol de un centro intermedio de expedición de instrumentos jurídicos que no estaba previsto originariamente para desarrollar la Ley 80 y limitar la autonomía administrativa (Duque, 2018). Sin embargo, con salvedad de las circulares, no se encuentra una competencia expresa para la expedición de instrumentos del hard law o soft law, razón por la que se insinúa su inconstitucionalidad y/o ilegalidad (Benavides, 2018).

También se advierte que sus competencias están restringidas por los regímenes exceptuados, en virtud de la ley que les dio esta competencia (Gil, 2018). Sin embargo, conforme a la Sentencia C-037 del 2000 de la Corte Constitucional, las entidades excepcionadas no pueden inaplicar estas circulares, por su carácter obligatorio y presunción de legalidad. Ahí CCE está extralimitándose en sus funciones frente a las entidades excepcionadas (Gil, 2018).

El reconocimiento de CCE como ente productor de normas -de hard law o soft law- impone reconocer que existen unas potestades normativas a su cargo -informales, ilegales, inconstitucionales, o, conformes con el sistema jurídico-, que se deben controlar. El Consejo de Estado ha limitado un amplio número de competencias, al evidenciar unas funciones normativas que no son autónomas; sino de segundo orden, que deben respetar el principio de legalidad, la autonomía de la voluntad de las entidades públicas y la potestad reglamentaria del Presidente de la República (Sentencia del 11/04/2019, Exp. 52.055).

El control a estas facultades es necesario ya que la ausencia de control implica admitir "una nueva fuente del Derecho por la puerta trasera, con efectos que trascienden a los del propio reglamento y se equiparan a los de la Ley parlamentaria” (Sarmiento, 2011, p. 263) y, en nuestra jurisdicción apenas se abren las puertas para su control, aunque enfocado en los instrumentos del hard law (C.E. Auto del 19 de julio de 2018. Exp. 56307A). 
En consecuencia, debe reconocerse la existencia de nuevos instrumentos normativos expedidos por CCE, valorarse su legalidad en cuanto a su naturaleza, efectos, procedimiento y competencia para su expedición y consecuencias de su incumplimiento. Aspectos que deben ser controlados independientemente de su naturaleza de hard law o soft law, ya que se impone una tutela judicial efectiva desde el Estado Social de Derecho, este mínimo de protección es ineludible: no hay actos administrativos sin control, no deben existir instrumentos de CCE sin control.

\section{Referencias}

Alexy, R. (1993). Teoría de los Derechos Fundamentales. E. Garzón Valdés (Tr.) Madrid: Centro de Estudios Constitucionales.

Ariño Ortiz, G. (2003). Principios de Derecho Público Económico. Bogotá: Universidad Externado de Colombia.

Benavides, J. L. (2008). El contrato estatal. Entre el derecho público y el derecho privado. $2^{a}$ edición. Bogotá: Universidad Externado de Colombia.

Benavides, J. L. (2014). Contratos públicos. Estudios. Bogotá: Universidad Externado de Colombia.

Benavides, J. L. (2016). Tendencias generales de la contratación pública en América Latina. Bogotá: Universidad Externado de Colombia.

Benavides, J. L. (2018). Reformas recientes al régimen de contratación pública en el marco de la globalización del Derecho administrativo. XII Jornadas de Derecho Administrativo. Universidad de Antioquia y Eafit, Medellín.

Colombia Compra Eficiente. (2016). Guía de garantías en procesos de contratación.

Colombia Compra Eficiente. (2017). Guía para el manejo de ofertas artificialmente bajas en procesos de contratación.

Colombia Compra Eficiente. (2018). Respuesta a derecho de petición del 29 de octubre de 2018. Radicado 2201813000009547.

Colombia Compra Eficiente. (2018a). Guía para facilitar la circulación de facturas emitidas en desarrollo de un contrato.

Consejo de Estado. (2010). Sentencia del 14 de abril de 2010. Exp. 36054. [C.P. Enrique Gil Botero].

Consejo de Estado. (2010). Sentencia del 9 de diciembre de 2010. Exp. 39093. [C.P. Ruth Stella Correa Palacio].

Consejo de Estado. (2012). Sentencia del 29 de agosto de 2012. Exp. 37785. (C.P. Danilo Rojas Betancourth).

Consejo de Estado. (2017). Auto del 13 de octubre de 2017. Exp. 57875. [C.P. Carlos Alberto Zambrano].

Consejo de Estado. (2017). Auto del 14 de agosto 2017. Exp. 58820. [C.P. Jaime Orlando Santofimio Gamboa].

Consejo de Estado. (2017). Auto del 29 de marzo de 2017. Exp. 56307. [C.P. Carlos Alberto Zambrano]. 
Consejo de Estado. (2018). Auto del 19 de julio de 2018. Exp. 56307A. [C.P. María Adriana Marín].

Consejo de Estado. (2019). Sentencia del 11 de abril de 2019. Exp. 52055. [C.P. María Adriana Marín].

Contraloría General de Bogotá. (2018). Respuesta a derecho de petición del 16 de octubre de 2018. Radicado 2-2018-21566.

Contraloría General de Medellín. (2018). Respuesta a derecho de petición del 17 de septiembre de 2018. Radicado 047700-201800004245.

Corte Constitucional. (1997). Sentencia C-491 de 1997. [M.P. José Gregorio Hernández Galindo].

Corte Constitucional. (2001). Sentencia C-949 de 2001. [M.P. Clara Vargas Hernández].

Corte Constitucional. (2002). Sentencia C-508 de 2002. [M.P. Alfredo Beltrán Sierra].

Corte Constitucional. (2007). Sentencia C-491 de 2007. [M.P. Jaime Córdoba Triviño].

Corte Constitucional. (2016). Sentencia C-126 de 2016. [M.P. Jorge Pretelt Chaljub].

Corte Constitucional. (2017). Sentencia C-004 de 2017. [M.P. Alejandro Linares Cantillo].

Dávila Vinueza, L. G. (2001). Régimen Jurídico de la Contratación Estatal. Bogotá: Legis.

De Otto, I. (2001). Derecho Constitucional. Sistema de fuentes. Barcelona: Editorial Ariel S.A.

De Vivero, F. (2013). Las funciones de consulta y expedición de circulares asignadas a la Agencia Nacional de Contratación. En: Tratado general de los contratos públicos. Buenos Aires: La Ley.

Díaz Diez, C. (2013). La Jurisdicción de lo Contencioso Administrativo. Medellín: Universidad de Antioquia. CEDA. Librería Jurídica Sánchez R. Ltda.

Duque Gutiérrez, J. I. (2018). Entrevista.

Gil Álzate, W. (2018). Entrevista.

González López, E. (2017). La potestad reglamentaria de las comisiones de regulación como autoridades administrativas independientes. Bogotá: Universidad Externado de Colombia.

Guastini, R. (1999). Distinguiendo: estudios de teoría y metateoría del derecho. Barcelona: Gedisa.

Marín Cortés, F. (2010). Los servicios semipúblicos domiciliarios. Bogotá: Temis.

Marín Cortés, F. (2015). El Reglamento como fuente del derecho administrativo. (Texto inédito).

Marín Cortés, F. (2018). Reformas recientes al régimen de contratación pública en el marco de la globalización del Derecho administrativo. XII Jornadas de Derecho Administrativo. Universidad de Antioquia y Eafit, Medellín.

Martínez Jurado, D. (2018). El soft law en derecho administrativo y su control judicial en Colombia. Revista Digital De Derecho Administrativo, (20), 289-343.

Morón Urbina, J.C. (2018). Las competencias normativas de las autoridades administrativas peruanas en materia de contratación estatal en Perú. Revista Digital de Derecho Administrativo, (19), 119-157.

Osorio, J.D. (2018). Reformas recientes al régimen de contratación pública en el marco de la globalización del Derecho administrativo. XII Jornadas de Derecho Administrativo. Universidad de Antioquia y Eafit, Medellín.

Safar Díaz, M. (2017). La reivindicación de competencias de Colombia Compra Eficiente por el Consejo de Estado. Revista Digital De Derecho Administrativo, (19), 159-179. 
Sánchez Pérez, A. (2012). Las normas de derecho blando. Bogotá: Universidad Externado de Colombia.

Santaella Quintero, H. (2017). El doble nivel, vinculante y no vinculante, de la reglamentación en la contratación pública en Colombia. En: Contratos Públicos. (pp. 783 y ss.). Bogotá: Universidad Externado de Colombia.

Santos Rodríguez, J. (2018). Las facultades reglamentarias de la Agencia Nacional de Contratación Pública Colombia Compra Eficiente. Revista Digital de Derecho Administrativo, (19), 341-347.

Sarmiento Ramírez-Escudero, D. (2011). La autoridad del Derecho y la naturaleza del soft law. Cuadernos de Derecho Público, (28), 221-265.

Schimdt-Assmann, E. (2003). La teoría general del derecho administrativo como sistema. Madrid: Editorial Marcial Pons.

Suárez Tamayo, D. (2010). Huida del Derecho Administrativo: El caso de los servicios públicos domiciliarios. Medellín: Universidad de Antioquia.

Suárez Tamayo, D. (2013). Concepto de regulación en servicios públicos domiciliarios en la doctrina y jurisprudencia colombiana -1991-2010-. En: Letras Jurídicas. 18(1), 23- 64. 